\title{
EVALUATION OF BREAST DISEASE BY CLINICAL BREAST EXAMINATION (CBE): EXPERIENCE OF A TERTIARY CARE HOSPITAL
}

\author{
R AKHTER ${ }^{1}$, F DEEBA $^{2}$, MM HOSSAIN $^{3}$, B NASREEN $^{4}$, J BANU $^{5}$, M AMANULLAH $^{6}$, F AMBIA $^{7}$
}

\begin{abstract}
:
Introduction: Breast cancer is the second most common cancer $(10.4 \%$ of all cancer incidence, both sexes counted) and the fifth most common cause of cancer death in the world. In 2005, breast cancer caused 502,000 deaths worldwide. Clinical evaluation could function as a valuable diagnostic tool. Clinical evaluation, however, is a simple method to detect cases as it is inexpensive and non-invasive and if found to be accurate, might be of great value.

Aim: To evaluate patients referred to colposcopy clinic in BSMMU for breast symptoms by clinical breast examination (CBE).

Material and method: The study design was cross sectional study done in the colposcopy clinic in the department of Obstetrics and Gynaecology, under the 'Establishment of National centre for cervical and breast cancer screening and training at BSMMU' and 'Cervical and breast cancer screening and training in BSMMU' projects.

Result: A total of $\mathbf{7 5 2}$ patients fulfilled the inclusion criteria, demographic features are demonstrated in mean age of the patients was $35.1 \pm 9.2$ years, mean BMI was $22.5 \pm 2.1$, about $30 \%$ subjects were postmenopausal and about $2 \%$ patients had history of breast cancer. Presenting complaint was a self-detected breast mass and found to have a mass on examination by her physician in 204 patients. 308 subjects complained of mastalgia; 34 patients complained of nipple discharge. Only 5 patients complained of axillary lymph node enlargement. Nipple abnormalities like retracted and cracked nipple was complained by $4 \%$ cases. Most patients $(58 \%)$ were found to have normal findings. Palpable mass was found in 121 cases and bilateral in one case. Nipple abnormalities found in 10 cases. Tenderness and nipple discharge found in $15 \%$ and $4 \%$ cases respectively. Regarding the characteristics of the masses proved by cytology (FNAC), 109 were benign and 12 were malignant.

Conclusion: CBE is an important screening procedure to identify breast pathology. Out of 752 patients breast pathology were identified in about $41 \%$ of patients and $10 \%$ breast lumps were malignant. So CBE should be done every three yearly in $<40$ and yearly in above $\mathbf{4 0}$ years women.
\end{abstract}

Key words: CBE, Breast Cancer, Breast lump.

1. Dr. Rehana Akhter, Deputy Project Director, ENCCBCST, Bangabandhu Seikh Mujib Medical University, Dhaka, Bangladesh

2. Dr. Farzana Deeba, Assistant Professor, Department of Obstetrics and Gynaecology, Bangabandhu Seikh Mujib Medical University, Dhaka, Bangladesh

3. Dr. Mir Mosarraf Hossain, MBBS, DEM, MD (Endo \& Metabolic disorder), Assistant Professor, Department of Medicine, Dinajpur Medical College, Dinajpur, Bangladesh.

4. Dr. Begum Nasreen, Associate Professor, Department of Obstetrics and Gynaecology, Bangabandhu Seikh Mujib Medical University, Dhaka, Bangladesh

5. Dr. Jesmin Banu, Associate Professor, Department of Obstetrics and Gynaecology, Bangabandhu Seikh Mujib Medical University

6. Dr. Masuma Amanullah, Consultant (deputed), Department of Obstetrics and Gynaecology, Bangabandhu Seikh Mujib Medical University

Correspondence to: Dr. Rehana Akhter, Deputy Project Director, ENCCBCST, Bangabandhu Seikh Mujib Medical University, Dhaka, Bangladesh, e-mail: rehenaakhter 70@yahoo.com

\section{Introduction:}

A young woman presenting with a breast mass raises anxiety in both patient and family regarding the possibility of breast cancer. ${ }^{1}$ Breast cancer is the second most common cancer $(10.4 \%$ of all cancer incidence, both sexes counted) and the fifth most common cause of cancer death in the world ${ }^{2}$. In 2005, breast cancer caused 502,000 deaths worldwide (7\% of cancer deaths; almost $1 \%$ of all deaths ${ }^{3}$. Onefourth of women suffer from breast disease in their life time ${ }^{2-3}$.

In Bangladesh Breast cancer is the second most common cancer among women and hospital data shows that it constitutes $13-17 \%$ of female cancer. ${ }^{4}$ With the improvement in health care and increasing life expectancy, more and more women are being 
exposed to the risk of developing breast cancer. Breast lump is a very sensitive issue for the patient so a reliable, non-invasive and prompt diagnosis helps to lessen the associated anxiety and leads to early definitive treatment. Timely and accurate diagnosis of a breast lump with early intervention can bring down morbidity and mortality of malignant disease.

There are various modalities for the diagnosis of a breast lump such as mammography, ultrasonography, fine needle aspiration cytology (FNAC) but none of them are without impunity ${ }^{5}$.Early work by Magarey CJ et al. ${ }^{6}$ was concerned with the development of a management plan for the outpatient diagnosis of breast symptoms and they concluded that in the majority of patients the presence or absence of malignancy can be established with a high degree of certainty before biopsy.

Clinical evaluation could function as a valuable diagnostic tool. Clinical evaluation, however, is a simple method to detect cases as it is inexpensive and non-invasive and if found to be accurate, might be of great value ${ }^{7}$. This would prove to be highly useful particularly in areas where funds and/or facilities may not be available for more sophisticated diagnostic methods. ${ }^{8}$ The systematic use of the clinical examination criteria and the organizational platform would allow the clinicians to select malignant cases and plan inpatient/outpatient surgical treatment so as to avoid unnecessary admissions which will reduce hospital bed occupancy and expenditures incurred on the part of the patient.

However, Crone P et al. ${ }^{9}$ found that while the diagnostic sensitivity of clinical examination was high, around $98 \%$, the specificity was rather low, averaging $48 \%$. In addition, the study disclosed a statistical possibility of overlooking a few malignant tumors when using these three procedures and they recommended excision of all palpable breast lumps.

There is an overall consensus that clinical breast examination (CBE) is useful in screening as well as in evaluation of a lump. About $3 \%$ to $45 \%$ of cancer diagnoses missed by mammography were reported as having been detected by CBE. Although the sensitivity of mammography is greater than that of $\mathrm{CBE}$, there is a residual diagnostic value of $\mathrm{CBE}$ that favors its continued use in screening ${ }^{10}$.

The screening strategies of Western countries may not be suitable for Bangladesh because of the many differences between Asian and Caucasian women with respect to the physiology of mammary glands (breast size and density) and the clinical characteristics of breast cancers (peak age incidence) ${ }^{9}$. The strategies of wealthier countries, including developed Asian countries, may also be unsuitable for Bangladesh because of differences in health care resources. Thus, in current socio-economic condition of Bangladesh, a combination of CBE and SBE are being introduced at national level for breast cancer detection. If SBE and CBE suspect any growth or abnormalities, the woman should be referred. And could be performed during VIA or pap smear.

According to guidelines followed by American Cancer Society for breast cancer screening, woman of 20-39 years should have a clinical examination of breast (CBE) at least every three years and $>40$ years every year, performed by health care professional such as physician, nurse, physician assistant. CBE can be performed during pap smear ${ }^{11}$.

Aim: To evaluate patients referred to colposcopy clinic in BSMMU for breast symptoms by clinical breast examination (CBE).

\section{Material and Method:}

The study design was cross sectional study done in the colposcopy clinic in the department of Obstetrics and Gynaecology, under the 'Establishment of National centre for cervical and breast cancer screening and training at BSMMU' and 'Cervical and breast cancer screening and training in BSMMU' projects. The records of women who referred with a breast lump or referred for breast examination to Bangabandhu sheikh Mujib Medical University at colposcopy clinic , during the time period January 2009 to July 2013 were studied. Structured proformas were filled based on the information obtained from the individual patient. CBE was done and patients with breast lump and suspected malignancy were referred for imaging and FNAC for confirmation of diagnosis.

\section{Study inclusion criteria were:}

- Women (over the age of 21) referred for evaluation of a particular area of concern identified either by the woman herself or her primary physician and who were willing to participate in the screening were eligible for the study.

\section{Study exclusion criteria were:}

- patients with skin infection or inflammation in the breast, 
- patients with prior breast cancer surgery or radiation,

- patients with scleroderma or other connective tissue

- Pregnant or lactating women

- Women with existing untreated malignancies, known metastatic disease

- Conditions that precluded fully informed consent

Clinical Breast Examination: Clinical examination of the breast is a physical examination of breast, includes inspection and palpation of entire breast and regional lymphatic areas (including the lateral and medial borders and axilla) ${ }^{12}$.

\section{Result:}

A total of 752 patients fulfilled the inclusion criteria , demographic features are demonstrated in Table 1. The mean age of the patients was $35.1 \pm 9.2$ years, mean BMI was $22.5 \pm 2.1$, about $30 \%$ subjects were postmenopausal and about $2 \%$ patients had history of breast cancer.

Table-I

Socio demographic features of the study subjects $(n=752)$

\begin{tabular}{lc}
\hline Age (years) & $35.1 \pm 9.2$ \\
Mean & \\
Range & \\
BMI(kg/m3) & \\
Mean & \\
Range & $22.5 \pm 2.1$ \\
Menstrual status (no \%) & \\
Pre menopausal & $540(70.1 \%)$ \\
Post menopausal & $212(29.9 \%)$ \\
Parity (no \%) & \\
Naliparous & $224(29.8 \%)$ \\
Multiparous & $528(70.2 \%)$ \\
History of OCP (no \%) & \\
Yes & $342(45.5 \%)$ \\
No & $410(54.5 \%)$ \\
Family history of breast ca (no \%) & \\
Yes & \\
$13(1.7 \%)$ & \\
No & $739(98.2 \%)$ \\
History of benign breast disease (no\%) \\
Yes & $119(15.8 \%)$ \\
No & $633(84.2 \%)$ \\
\hline
\end{tabular}

Table II showed, the presenting complaint was a selfdetected breast mass and found to have a mass on examination by her physician in 204 patients. 308 subjects complained of mastalgia; 34 patients complained of nipple discharge. Only 5 patients complained of axillary lymph node enlargement. Nipple abnormalities like retracted and cracked nipple was complained by $4 \%$ cases.

Table-II

Complains of the subjects $(n=752)$

\begin{tabular}{lcc}
\hline Complains & Number & Percentage \\
\hline Pain & 308 & 40.95 \\
Lump & 204 & 27.12 \\
Nipple discharge & 34 & 4.52 \\
Nipple abnormalities & 35 & 4.65 \\
Lymphadenopathy & 5 & 0.66 \\
Others & 166 & 22.07 \\
\hline
\end{tabular}

Findings on clinical examination are summarized in Table 3. Most patients (58\%) were found to have normal findings. Palpable mass was found in 121 cases and bilateral in one case. Nipple abnormalities found in 10 cases. Tenderness and nipple discharge found in 15\% and $4 \%$ cases respectively.

Table-III

CBE findings ( $n=752)$

\begin{tabular}{lcc}
\hline Findings & Number & Percentage \\
\hline Normal & 440 & 58.51 \\
Lump & 121 & 16.09 \\
Fibrocystic disease & 32 & 4.25 \\
Tenderness & 115 & 15.29 \\
Nipple discharge & 34 & 4.52 \\
Nipple abnormalities & 10 & 1.33 \\
\hline Total & 752 & 100 \\
\hline
\end{tabular}

Regarding the characteristics of the masses proved by cytology (FNAC), 109 were benign and 12 were malignant (Table-IV).

Table-IV

Histopathological findings of breast lump

\begin{tabular}{lcc}
\hline Histopatholigical findings & Number & Percentage \\
\hline Malignant & 12 & 9.92 \\
Benign & 109 & 90.08 \\
\hline Total & 121 & 100 \\
\hline
\end{tabular}




\section{Discussion:}

The study design was cross sectional study done in the colposcopy clinic in the department of Obstetrics and Gynaecology, under the 'Establishment of National centre for cervical and breast cancer screening and training at BSMMU' and 'Cervical and breast cancer screening and training in BSMMU' projects.

The incidence of breast cancer increases with age doubling about every 10 years until menopause then the rate of increase slows dramatically ${ }^{12-13}$.The agestandardized incidence of breast cancer for women in the USA is 124.0 per 100,000 women per year, with a median age at diagnosis in the United States of 61 years ${ }^{14}$. The mean age of the study subjects were $35 \pm 9$. 2 years. About $30 \%$ women were post menopausal.

Obesity is associated with twofold increase in risk of breast cancer in post menopausal age group whereas among premenopausal woman it is associated with a reduced incidence ${ }^{13}$. In the study the mean BMI was $22.5 \pm 2.1 \mathrm{~kg} / \mathrm{m}^{3}$.

Previous pregnancy may have been a contributing factor as described in previous reports ${ }^{15}$. Naliparity is associated with the life time incidence of breast cancer $^{16}$. About $30 \%$ patients were naliparous in the study and $70 \%$ patients were multiparous.

Upto $10 \%$ of breast cancers in western countries are due to genetic predisposition. Woman having history of benign breast disease and family history of breast cancer (first degree relatives) have a nine fold increased risk $^{16}$. History of benign breast was found in $15 \%$ cases, but there was no patient with history of breast cancer.

Many studies have shown that oral contraceptive pill (OCP) use is associated with an increase in a young woman's risk of breast cancer ${ }^{13-15}$, although some studies suggest that the risk may be limited to recent use $^{17}$. In the study the $45.5 \%$ responders had a history of use of OCP.

Majority of women who come to the surgical OPD complain of either pain or lump in the breast or discharge from the nipple ${ }^{4}$, which is similar to our study. $40 \%$ patients complained of pain, $27 \%$ of lump, $9 \%$ of nipple discharge, minority had other complains.

The breast pathology distribution observed in this study is in agreement with the data received from large scale screening and research trials ${ }^{11,18-20}$. Out of 752
Subjects, $59 \%$ had no abnormality in CBE. $4 \%$ subject had lumpy fibrocystic breast, definite lump found in 121 cases and $6 \%$ had nipple discharge.

A review of 357 patients aged 25 years or less with a breast mass consistent with a fibroadenoma (clinically and on ultrasound), $0.8 \%$ were found to have a benign phyllodes tumor, and $0.3 \%$ had a breast carcinoma, the rest had benign disease ${ }^{21}$. Early presentation of breast carcinoma in a young woman may be very similar to that of fibroadenoma ${ }^{22}$. Among the patients who had definite lump, imaging and or cytology was done by the decision of the surgical colleagues. 12 patients proved to had malignancy and 109 patients had benign breast lump mainly fibroadenomas.

The present study include the use of CBE as a screening procedure as well as to identify the breast pathology of the patient who were referred for breast problem. However, the study also has several limitations. First, it was conducted at a single site, which might have resulted in selection bias. The quality of clinical breast examination needs to be increased by standardizing examination procedures. Careful, systematic palpation has been shown to increase detection of breast lumps. Patient position, palpation of breast boundaries, and examination pattern and technique are important variables in CBE ${ }^{23}$. Largesample and multicentre clinical studies with trained professional in CBE could be done.

\section{Conclusion:}

$\mathrm{CBE}$ is an important screening procedure to identify breast pathology. Out of 752 patients breast pathology were identified in about $41 \%$ of patients and $10 \%$ breast lumps were malignant. So CBE should be done every three yearly in $<40$ and yearly in above 40 years women.

\section{References:}

1. Simmons PS. Breast disorders in adolescent females. Curr Opin Obstet Gynecol 2001;13: 45961.

2. Curado MP. Breast cancer in the world: incidence and mortality. Salud Publ Mex 2011; 53:372-384.

3. Meads C, Ahmed I, Riley RD: A systematic review of breast cancer incidence risk prediction models with meta-analysis of their performance. Breast Cancer Res Treat 2011; 22:45-49.

4. Huq SF. Common cancers of Bangladesh: their trends through last three decades. Bangladesh Medical Journal 1988; 17(3):55-63 
5. Prasad SN, Houserkova D. A comparison of mammography and ultrasonography in the evaluation of breast masses. Biomed Pap Med Fac Univ Palacky Olomouc Czech Repub 2007; 151:315-322

6. Magarey CJ, Watson WJ Med. The outpatient diagnosis of breast lumps. J Aust 1976; 46: 344-349.

7. Hampton T. Breast cancer symposium highlights risk, recurrence, and research trials. JAMA 2012; 307:348-350.

8. Magarey CJ. Detection and diagnosis of early breast cancer. Med J Aust 1976; 2:834-837.

9. Crone P, Hertz J, Nilsson T. The predictive value of three diagnostic procedures in the evaluation of palpable breast tumours. Ann Chir Gynaecol 1984; 7:273-276.

10. Barton MB, Harris R, Fletcher SW. Does this patient have breast cancer? The screening clinical breast examination: Should it be done? How? JAMA 1999; 282:1270-1280. doi:10.1001/ jama.282.13.1270.

11. American Cancer Society: breast cancer facts \& Figs. American Cancer Society; Atlanta: 2007-2008.

12. Honjo S, Ando J, Tsukioka T, et al. Relative and combined performance of mammography and ultrasonography for breast cancer screening in the general population: a pilot study in Tochigi prefecture, Japan. Jpn J Clin Oncol 2007; 37: 715-20.

13. Akhter PS, Uddin MM, Sharma SK. Pattern of malignant neoplasm- A three years study. Bangladesh Medical Journal 1998; 27(2):29-32.

14. Howlader N, Noone AM, Krapcho M, Neyman N, Aminou R, Waldron W, Altekruse SF, Kosary CL, Ruhl J, Tatalovich Z, Cho H, Mariotto A, Eisner MP, Lewis DR, Chen HS, Feuer EJ, Cronin KA,
Edwards BK, editors. SEER Cancer Statistics Review, 1975-2008. National Cancer Institute; Bethesda, MD: 2011.

15. Beadle BM, Woodward WA, Middleton LP, Tereffe W, Strom EA, Litton JK, et al. The impact of pregnancy on breast cancer outcomes in women<or=35 years. Cancer 2009; 115(6): 1174-84.

16. Parkin DM, Bray FI, Devesa SS. Cancer burden in the year 2000. The global picture. Europian journal of cancer 2001; S44-S66: 37.

17. Holli K, Isola J, Cuzick J. Low biologic aggressiveness in breast cancer in woman using hormone replacement therapy. Journal of Clinlcal Oncology 1998; 16(9): 3115-3120.

18. Pisano ED, Gatsonis C, Hendrick E, et al. Diagnostic performance of digital versus film mammography for breast-cancer screening. $\mathrm{N}$ Engl J Med 2005; 353:1773-1783.

19. Skaane P, Hofvind S, Skjennald A. Randomized trial of screen-film versus full-field digital mammography with soft-copy reading in population-based screening program: follow-up and final results of Oslo II study. Radiology 2007; 244:708-717.

20. AltmannA, Hellerhoff K, Heywang-Köbrunner SH. Screening in women with increased breast cancer risk. Breast Care 2006; 1:22-25.

21. Smith G, Burrows P. Ultrasound diagnosis of fibroadenoma: is biopsy always necessary? Clin Radiol 2008; 63:511-515.

22. Shannon C, Smith IE. Breast cancer in adolescents and young women. Eur $\mathrm{J}$ Cancer 2003; 39: 2632-42.

23. Barton MB, Harris R, Fletcher SW. Does this patient have breast cancer? The screening clinical breast examination: Should it be done? How? JAMA 1999; 282:1270-1280. doi: 10.1001/ jama.282.13.1270. 